\title{
Accessibility to the historic defence sites of Oman for people with mobility impairment: the cases of the Nakhal, Al Hazm and Khasab fortifications
}

\author{
M. A. K. Al-Belushi \\ Department of Archaeology, College of Arts and Social Sciences, \\ Sultan Qaboos University, Sultanate of Oman
}

\begin{abstract}
Providing access to the old defence buildings for people with mobility impairment represents one of the foremost challenges that are facing heritage managers all over the world. Introducing access to such buildings is not an easy issue as it disturbs the authenticity of the place and its inherent values and significance. This paper aims to study the issue of providing accessibility to the historic defence sites of Oman for people with mobility impairment. It focuses on the restored historic forts and castles that are currently utilized as touristic sites. The significant fortifications of Nakhal, Al Hazm and Khasab have been investigated as case studies to provide a preliminary overview about the current status of such type of accessibility, and the challenges confronting heritage and tourism managers to enable wheelchair users to access these sites without compromising their heritage values. Finally, the paper concludes that despite the efforts made to make some of these defence structures accessible for people with mobility impairment, there is a pressing need to set out a national strategy to determine access requirements to such structures and to offer practical solutions that conform to the issues of people's equity and sites' authenticity and value.

Keywords: accessibility, mobility impairment, Sultanate of Oman, Khasab Castle, Al Hazm Castle, Nakhal Fort, defence sites, heritage management.
\end{abstract}




\section{Introduction}

Oman has a large number of historic defence sites, mostly in the form of castles, forts and towers. Some of these fortifications extend to periods prior to Islam. The government has made enormous progress in managing and protecting this heritage $[1,2]$. Within this trend which began nearly four decades ago and continues to this day, a large number of forts and castles have been restored and presented to the public as part of the country's tourist attractions [1]. Most of the restoration projects have been carried out with Moroccan expertise under a 1983 agreement between the Ministry of National Heritage and Culture and the Moroccan government. Restoration of the historic forts and castles of Jabreen, Bahla, Al Rustaq, Nizwa, Nakhal, Mutrah, Sohar, Al Hazm, and Quriyat are among the finest examples of these projects [1].

Within the framework of introducing this heritage to the public, the Directorate General of Tourism (previously part of the Ministry of Commerce and Industry, and now belonging to the Ministry of Tourism), started in 2000 a project to utilize twenty-three restored forts and castles from the different regions of the country as tourist attractions. A plan has been formulated to adapt these fortifications and considerable resources have been set aside for this purpose with the anticipation that this tourist focus will be used partly to conserve and maintain these fortifications [1]. Forts and castles were selected based on their state, and on their geographical distribution. All are in good condition and are distributed throughout all of the country's administrative regions [1]. Today, these forts and castles are partly furnished with old weapons and ethnographic materials that reflect the local culture of the places in which they are located. Additionally, a number of small museums, libraries and souvenir shops have been introduced to some of these fortifications. Some of them also provide tour guides and brochures.

Despite these efforts, the number of visitors to these monuments is still less than anticipated. Official statistics indicate that the number of visitors to these fortifications in 2010, 2011 and 2012 was 202,000; 177,000; and 186,000 visitors respectively [3]. There is no information about the number of disabled visitors. Moreover, the ability of these buildings to receive disabled people, particularly those with mobility impairment has not yet been evaluated.

Although Omani laws and regulations clearly stresses the principles of equity between members of the community in all aspects of life, the application of those principles in such heritage sites for people with special needs is still blurred and non-systematic. Furthermore, guidelines, codes of practices and measures on how to deal with disabled people in such sites have not yet been established by heritage and tourism organizations. Therefore, the significance of this study stems from the fact that it is the first attempt to assess the current status of providing accessibility to the historic defence sites of Oman for people with mobility impairment. It will examine this issue from a heritage management perspective. It will also review the current Omani legislative framework regulating the rights of disabled people to access heritage and historic sites. Three case studies will be examined systematically in order to observe the way that Omani defence heritage sites treat disabled access. It is hoped that this study will draw the attention of the decision 
makers, tourism planners and heritage managers in Oman to the importance of having codes and guidelines regulating the issue of access to heritage and historic sites for people with impaired mobility.

\section{Methodology}

In order to assess the current status of disabled access to the forts and castles, site visits were carried out to the twenty-three restored fortifications that are currently utilized by the Ministry of Tourism as tourist attractions. These are the fort of Murtha and the castle of Quriyat (in Muscat Governorate), the castles of Barka, Al N'uman, As Suwayq, Al Hazm, and the forts of Al Rustaq and Nakhal (in Al Batinah Governorates), Khasab Castle (in Musandam Governorate), the castles of Al Hillah and Al Khandaq (in Al Buraimi Governorate), the castle of Ibri (in Al Dhahirah Governorate), the castles of Bayt al Ridaydah and Jabreen and the fort of Nizwa (in Al Dakhliyah Governorate), the castles of Al Mintarib, Jaalan Bani $\mathrm{Bu}$ Hasan, Ras Al Hadd, Bilad Sur and Sunaislah (in the Ash Sharqiyah Governorates), and the castles of Taqah, Mirbat and Sadah (in Dhofar Governorate). These monuments reflect the cultural and geographical variations of the country.

In order to acquire an in-depth overview about the current adaptation methods used for mobility impairments in the Omani old defence structures, the significant forts of Khasab, Al Hazm and Nakhal have been investigated as case study examples. They were chosen because of the distinctive variations of their structures, and because of their popularity amongst tourists. Through these examples, the study has tried to pinpoint the challenges that might confront heritage managers and tourism planners in their endeavor to enable wheelchair users to access these sites without compromising their authenticity and heritage values. Data related to the case studies have mainly been collected based on site visits. Additional information was acquired through literature and archives search. The websites of both Ministry of Tourism and Ministry of Heritage and Culture offered some statistics about these fortifications. Furthermore, various other formal documents were surveyed, including royal decrees, legislations, conventions and ministerial decisions related to the rights of disabled people, as well as to the structures and duties of the organizations responsible for heritage and tourism.

\section{Forts of Oman}

Oman is a country with diverse terrain and environment, with a total area of $309,500 \mathrm{~km}^{2}$ and a total population of 3,623,001 (Omanis = 2,092,560; Expat = $1,530,441)$ as of mid-2012 [3]. The strategic position between the East and the West has enabled Oman to play a major role in the trade of the Indian Ocean and Arabian Gulf during the sixteenth and seventeenth centuries. By the seventeenth century, Oman became an empire, and competed with European powers such as the Portuguese, Dutch and British to control the trade routes of the East. Amongst the most influential of these powers at that time were the Portuguese who occupied 
some parts of Oman for a period of 143 years between 1507 and 1650 [4]. To protect the places they had controlled, the Portuguese built a number of castles and forts at strategic locations. The influence of the Portuguese architectural style of defence can still be seen reflected in the old fortifications of Oman until today, despite the fact that the forts that were built by Portuguese were re-built and enlarged by the Omanis in the succeeding periods. As Salma S. Damluji describes in her book The Architecture of Oman, 'the forts and castles of Oman represent the most obvious feature in traditional Omani architecture. Crowning cities, and commanding the entrances to towns, they continue to have a dominant presence in the urban landscape. The design layout and building technology of this fortified architecture, which included residential spaces, is indicative of the level of sophistication that town planning and architecture reached in settlements across the Sultanate. The forts have remained a focal point for visitors to the country and a basic historic reference for the surrounding fabric of adjacent towns, despite the removal, through renewal or reconstruction, of the surrounding traditional fabric' [5].

With the unprecedented development which started in the country in the early 1970s, these historic fortifications took on a different perspective [6]. Today, these structures do not reflect their status of the past, and have long since ceased to be an integral part of the peoples' daily lives. They merely form a visual backdrop of the place and the role assigned to them now can best be described as minor and decorative [7]. Most of these fortifications have been restored by the Ministry of Heritage and Culture and some of them are managed by the Ministry of Tourism.

The main characteristics of these fortifications can be summarized, based on $[8,6,9,10]$ in the following points:

- They were used to protect towns and harbors and guard the mountain passes and trade routes. They also served as centres of administration and justice. Many of them were used also as residences for the wali (local governor) and his family and entourage.

- $\quad$ Forts were built primarily for defensive purposes but many of them were used as bases for the rulers. Castles, on the other hand, were originally built to be prestigious habitations, but with defensive architectural style.

- The interiors of most of them are decorated with gypsum works and Arabic calligraphy and inscriptions.

- Forts are generally positioned on high altitudes on the top of rocky outcrops. Castles on the other hand, were largely built on flat areas but fortified with high thick walls.

- Their main building materials are stones, mud-bricks, mortar, gypsum, palm fronds and logs.

- Their walls are of immense thickness. They are high and contain loops for cannon and small arms firing.

- Their gates and doors are strong with an immense thickness and beautiful wooden decorations and carvings.

- Their internal structural plan is characterized with many obstacles that would face the attackers, like zigzags and narrow passages which always end at every turn with doors to obstruct the attackers. 
- Many forts and castles secure their water supply through wells that are dug inside the buildings or via the indigenous water tunnel system of aflaj which for security reasons runs below the ground in the surrounding area to guarantee source of water during war times.

\section{Current efforts}

The Ministry of Tourism is currently operating 23 restored forts and castles as tourist attractions and expected to soon receive another 31 fortifications after finishing their restoration, and ensuring their readiness to receive visitors. The ministry has formulated a development plan for each one of these sites [11]. These plans take into account the facilities that can serve people with physical disabilities. Hence, some forts and castles have been provided with facilities that make them able to receive people with mobility impairment. In addition to the tour guides, these facilities are equipped with ramps, and audio visual devices. For instance, in Jabreen Castle the Ministry of Tourism has introduced handheld audio guides to provide interpretation to all visitors in both Arabic and English versions. It is also planned to launch $3 \mathrm{D}$ visualization guides for those unable to access all parts of the castle. Likewise, there is a plan to provide visitors of Al Hazm Castle with the same audio guides, in addition to furnishing the various parts of the castle with sounds and visual effects [11]. Moreover, some of these forts and castles are equipped with temporary wooden ramps to help wheelchair users. Furthermore, the interpretive exhibitions and toilets have been placed on the ground floors of these fortifications in order to make them accessible to all categories of visitors. Nevertheless, the Ministry of Tourism currently has no comprehensive guidelines or codes of practices governing, and organizing the issue of disabled access to the heritage sites. Devising such guidelines would help in specifying standards, measures and procedures to be followed in this aspect. There is also no statistical data about the number of disabled people's visits to such sites [11]. This type of information can help in developing plans to add facilities that enable disabled people to visit the castles and forts and other archaeological sites.

\section{Legislation}

Oman is an Islamic country, and so equality, social solidarity and peaceful coexistence between people represent the main key principles of its community. However, the inclusion of principles related to equality and the rights of individuals with disabilities in the Omani modern legislation started to appear only since about four and a half decades. In general, existing Omani legislation stresses on the importance of providing all that would help people with physical disabilities access to public places and to deal with them through the principles of equality and equal opportunities. Today, the society does not look at the physically disabled people as dependent members with limited abilities. Instead, the law guarantees them the right of easy access to all sites equally with others. The law also obliges all stakeholders to provide disabled access for them. 
A review of current laws and regulations as well as international conventions signed by the Sultanate in the field of disability rights, show that the government has made notable progress in securing the rights of the disabled people. The Basic Statute of the State - which serves as the constitution of the country and the cornerstone on which other legislation is built - stresses the importance of justice, deliberation, equality and equal opportunities for citizens, and considers them the pillars of society guaranteed by the State [12: Articles 9, 10, 12]. The Basic statute also stresses that the state also guarantees assistance for citizens in case of disability in accordance with the scheme of social security [12: Article 12], and that all citizens are equal before the law and share the same public rights and duties. There shall be no discrimination between them on the grounds of gender, origin, colour, language, religion, sect, domicile, or social status [12: Article 17].

The Disabled Persons Welfare and Rehabilitation Law defines 'the disabled' as a person who suffers from a shortage of some of their physical or sensory or mental cognitive capacity, or the result of genetic factor, disease, or accident, limiting their ability to perform their natural role in life compared to those who are of their age, the thing that makes them in need for care and rehabilitation to adapt and integrate into society [13: Article 1]. As part of the responsibilities of the state towards people with disability, this law has exempted from customs taxes, the rehabilitative and compensatory tools and devices necessary for the disabled which are imported by rehabilitation centers or brought by disabled people for their personal use, taking into account the provisions stipulated in the customs laws [13: Article 2]. That same law also confirms the state responsibility to provide educational services for the disabled commensurate with their sensory, physical and mental abilities [13: Article 7]. It also confirms the commitment of the relevant government agencies to take the necessary measures to ensure the benefits of the disabled from public services. Amongst these measures are: (a) to adhere to the engineering specifications for places, roads, public buildings, places of worship and entertainment, entrances to markets, parking lots and the other facilities frequented by the disabled; (b) to provide public transport with the necessary amenities to facilitate their movement at airports, ports, and roads [13: Article 10]. In order to follow up on these aspects, the government has established through this law the "Oman Association for the Disabled" [13: Articles 13-15], as well as the "Disabled Care and Rehabilitation Centers" [13: Articles 16-18]. In addition to all this, the Sultanate has established "The National Human Rights Commission" [14] under the jurisdiction of State Council to observe human rights protection in Oman in line with The Basic Statute of the State, and the international charters and conventions [14]. At the international level, Oman has ratified The International Convention on the Rights of Persons with Disabilities without its optional protocol [15] and incorporated the principles and provisions of this convention into its national legislation.

Despite all these efforts, there are no legal provisions in Oman regarding the issue of creating access for the disabled in the heritage sites until this day. Reviewing the laws governing the work of the organizations responsible of tourism and heritage shows that this issue is absent in both the National Heritage Protection Law (NHPL) [16] and Tourism Law [17]. The NHPL classifies the 
components of the national heritage into registered and non-registered items [1, 18]. The NHPL protects the registered monuments by considering 'anyone who may damage, demolish, move, maim, vandalize, alter or tamper with any registered monument' as an offender who will be liable to a fine and/or imprisonment penalties [16: Article IX]. It also controls activities that could affect the registered monuments. It obliges anyone who wants to build 'any structure on a registered monument or within its visual field' to obtain written permission from the Ministry of Heritage and Culture [16: Article X]. This also applies to the work of restoring, renovating, expanding or repairing the 'existing buildings whether internally or externally' [16: Article XI]. Despite the fact that the system of registering monuments has not been established up to now, and that there is no such entity as 'registered monument' [18], the forts and castles of Oman (especially those restored and utilized for tourism purposes) have always been treated as of national importance. The fort of Bahla has been inscribed as a World Heritage Site in 1987 and the Ar Rustaq Fort and Al Hazam Castle have been added in 1988 to the Omani tentative list of sites in order to inscribe them on the World Heritage List. In addition to all this, until this day there is no guideline or code of practice for treating disabled in these sites.

\section{A proposed categorization}

Based on the characteristics of forts and castles and their current status in terms of access for people with physical disabilities, this study suggests that these defensive fortifications can be classified into three categories. These classifications include only castles and forts that are currently operated as tourist attractions by the Ministry of Tourism. The characteristics of each of these categories can be described as follows:

Category I: includes forts and castles that can receive the physically disabled in between $50-75 \%$ of their parts because of one or more of the following reasons: (a) consists of only one floor; (b) most of their parts can be visited by physically disabled; (c) easily accessible; (d) located on flat ground; (e) contain alternative entries; (f) pathways are paved; (g) few staircases; (h) stairs are with handrails; (i) wide entrances; (j) restrooms are easily accessible; $(\mathrm{k})$ additional facilities for disabled people such as lifts can be added to them in the future. This category could include the castles of Quriyat, Khasab, Al Hillah, Al Khandaq, Al Mintarib, Bilad Sur, Ras Al Hadd, and Sunaislah.

Category II: includes forts and castles that can partially receive the physically disabled in not more than $50 \%$ of their parts because of one or more of the following reasons: (a) consists of two floors or more; (b) physically disabled can visit at least parts of their lower floors; (c) paved floors; (d) some of their parts are accessible without the need to climb staircases; (e) located mostly on flat ground; (f) most pathways are paved; (g) wide entrances; (h) upper levels are accessible only through climbing tall staircases; (i) additional facilities for disabled people such as lifts can be added to them in the future. This category could include the fort of Nizwa and the castles of Al Hazm, Jabreen, An N'uman, Barka, Bayt ar Ridaydah, Ibri, Jaalan Bani Bu Hasan, Mirbat, and Taqah. 
Category III: includes forts and castles where it is currently difficult to receive people with mobility impairment. Instead, they can offer them the chance to see the external parts of their buildings and navigate the areas surrounding them. This is because of one or more of the following reasons: (a) often built on top of a hill or a mountain; (b) consist of complex and inconsistent structural levels imposed the topography of the outcrops on which they are located; (c) narrow entrances; (d) their various parts are connected through a complex set of narrow and tall staircases; (e) there are a lot of structural obstacles that may distract all types visitors because they were built primarily to be defensive strongholds; (f) currently no facilities or services for disabled accessibility; (g) difficult to introduce appropriate facilities for the physically disabled because of their complicated architecture. This category could include the forts of Mutrah, Nakhal and Al Rustaq, and the castles of As Suwayq and Sadah.

\section{Case studies}

\subsection{Category I: Khasab Castle}

This castle which dates back to the $17^{\text {th }}$ century was built by the Portuguese in order to dominate Musandam and the Strait of Hormuz. It was then restructured by the Omanis after the expulsion of the Portuguese. Until recent years, it was the local governmental quarter and home of the local governor. It has been restored and adapted into a museum [19]. It is located on the inner cove of Khasab bay [6]. It commands the shore and protects the village and the fertile valley beyond [9]. The castle is placed on a flat area. It is of a square shape with four bastions connected by curtain walls [6]. It is of one level except in the towers which consist of two levels. It has an open-air courtyard with a central tower in the middle. The courtyard is exhibited with traditional boats and houses reflecting people's adaptation to environment in this area. The floor of the courtyard is paved with local slabs of limestone. Hence, the exhibits of the courtyard can be accessed easily by people with mobility impairments. However, they will not be able to reach the inside areas of the replicated traditional houses. There is a central tower in the middle of the courtyard. It has been adapted as a museum with displays featuring the natural and cultural heritage of the area. This tower has an access for people with mobility impairment in the form of a permanent curved ramp attached to its outer part. The upper rooms of the corner towers feature traditional medicine, costume and jewelry in addition to the women's reception room, a wedding room and a Qur'an school. However, there is no access for wheelchair users to reach these rooms. The restrooms and gift shop which are located in the lower level are fully accessible for disabled people. It is expected that this castle will be an important tourist attraction as Khasab is undergoing an unprecedented development. A number of hotels and shopping malls are being under construction few metres away from this castle. Finally, the castle has won in 2010 a UK-based "Museums \& Heritage Awards for Excellence" in the international category. The prize was given to the Ministry of Tourism for its performance in upgrading the facilities at this castle and for encouraging new audiences to visit it [20]. 


\subsection{Category II: Al Hazm Castle}

This castle is located on a flat gravelly plain on the western bank of Wadi Far. It is surrounded by a cultivated area and houses [21]. It was built by the Imam Sultan bin Saif Al Yarubi in early eighteenth century. It is a large rectangular two storied building with a narrow inner courtyard and two round towers flanking the southern and eastern corners [21]. The castle is built for both defence and comfortable living [10]. Its interior is palatial while its outer appearance reflects its defensive massiveness [9]. Its walls are of a remarkable thickness. Its main door is of an immense thickness with about $20 \mathrm{~cm}$ high threshold. Its front entrance is accessible while the main door is accessible only by using temporary wooden ramp. Access to some parts of its ground floor is possible. The restoration process took into account the differences between the floor elevations in the lower level. The different elevations of the pathways in the ground level have been linked to each other by gentle slope permanent shallow ramps made of cement to permit wheelchair users to easily navigate the various parts of this level. Currently, wooden ramps are used to help people wheelchair users to cross the doors and to navigate parts of the lower level. On the other hand, the upper levels of the castle are not accessible for wheelchair users. The staircases leading to these levels are tall and most of them are narrow. The Ministry of Tourism is planning to provide visitors of Al Hazm Castle with audio guides in addition to furnishing the various parts of the castle with sounds and visual effects [11]. Today, this castle houses an artillery museum which contains various types of historic cannons from different parts of the world. This castle has been added in 1988 to the Omani tentative list of sites in order to inscribe it on the World Heritage List of UNESCO [21].

\subsection{Category III: Nakhl Fort}

Nakhal Fort is located on a rocky outcrop overlooking the gravely flat plain that separates the dense palm oasis of Nakhal and its mountains from the Batinah coastal plain. Nakhal is considered one of the important tourist destinations in the country due to its close proximity to the capital Muscat as well as the hot springs of Al-Thawarah and the major wadis of Mistal, Bani Awf and Bani Kharus which all descends from the southern part of the Al-Jabal Al-Akhdar. This location has given the fort of Nakhal its great importance as a tourist destination. The castle dates back to the period before Islam. It consists of six towers joined by a high wall with another separated tower in its center [10]. The fort was restored in 1990 and furnished with some cannons, traditional weapons and ethnographic exhibits that reflect the military history as well as the local culture of the place. According to statistics of the Ministry of Tourism, the number of visitors to the fort in 2010 was 18,850 visitors [22]. The fort has a number of tour guides, but not enough signs to direct visitors. It has been placed in this category because of its high altitude and the inconsistent heights of its level which is imposed by the tough topography of the outcrop on which it is located. It can be accessed via a steep asphaltic ramp that allows vehicles to reach the main gate or via a side tower attached to the entrance. This castle is characterized by its large number of tall and inclined staircases. The width of the staircases varies and is dictated by the 
topography of the outcrop. Access to the various parts of the fort should be via the staircases. Currently, no ramps or lifts are available in this fort. Due to the complex architecture of the fort, introducing such facilities will require drastic intrusive alterations to its structure which will no doubt, affect its historicity and authenticity values. Therefore, it is very difficult to modify this fort in order to receive visitors with physical disabilities. This can be substituted by establishing a museum near to the fort through which disabled visitors and other visitors can access its various parts virtually as well as through the tangible exhibits.

\section{Conclusions and recommendations}

This study has provided a preliminary assessment of the current status of the issue of providing accessibility to the historic defence sites of Oman for people with mobility impairment. It has shown that this issue has not yet been researched in Oman, and that it is, at least in terms of practice, still in its early stages. The study has also demonstrated that despite the fact that Omani legislation stresses on the rights of disabled people to access public places based on the principles of equality and equal opportunities, there are still no specific codes of practices and guidelines on which this issue should be treated. Furthermore, despite the efforts made to make some of the Omani historic defence structures accessible for people with mobility impairment, there is a necessity to set out a national strategy to determine access requirements to such structures, and to offer practical solutions that conform to the issues of people's equity and sites' authenticity and value.

\section{Acknowledgements}

I would like to express my deep appreciation to my wife Nawal, and to Ali and Maya, for their inspiration and encouragement. I would also like to thank Mr. Saif Al-Rawahi from the Ministry of Tourism for providing me information about the forts and castles of Oman, and Ms. Djeridi Nicola for her help in editing the text.

\section{References}

[1] Al-Belushi, M.A.K., Managing Oman's Archaeological Resource: Historical Perspectives. Public Archaeology, 7 (3), pp. 150-174, 2008.

[2] Al-Belushi, M.A.K., Characteristics of Oman's archaeological resource: a preliminary review of management prospects. Arabian Archaeology and Epigraphy, 25, pp. 121-137, 2014.

[3] National Centre for Statistics \& Information. Facts and Figures of 2012. Muscat, 2013.

[4] Holt, P.M.; Lambton, A.K.S. and Lewis, B., The Cambridge history of Islam, Cambridge University Press, 1977.

[5] Damluji, S.S., The Architecture of Oman. Garnet Publishing: Reading, UK, 1998. 
[6] Dinteman, W., Forts of Oman. Motivate Publishing: Dubai, Abu Dhabi and London, 1993.

[7] Al-Belushi, M.A.K., 2013. The heritage prospective and urban expansion in capital cities: old defence sites in Muscat, Oman. Presented in 'The 1st Conference on Defence Sites: Heritage and Future', Portsmouth, UK, and published in C.A. Brebbia (Ed.) Structural Studies, Repairs and Maintenance of Heritage Architecture XIII, Wessex Institute of Technology Transactions on The Built Environment, Southampton and Boston: WIT Press. ISSN 1743-3509 (on-line), doi: 10.2495/STR130461. Vol. 131: 551$562,2013$.

[8] Office of the Deputy Prime Minister for the Ministers Council Affairs, The citadels and forts of Oman, (in Arabic). Publication of Office of the Deputy Prime Minister for the Ministers Council Affairs: Muscat, 1994.

[9] Groves, P., Strongholds of Heritage: Forts and Castles of Oman. Motivate Publishing: Dubai, 2010.

[10] ICOMAM (The International Committee of Museums of Arms and Military History), Sultanate of Oman: Special issue. ICOMAM Magazine, 7, Basiliscoe Press \& ICOMAM: Leeds, UK, 2011.

[11] Personal communication: Mr. Saif Al-Rawahi, Ministry of Tourism, Oman, 19.06.2014.

[12] Royal Decree 101/1996, The Basic Statute of the State, Official Gazette (in Arabic), Muscat, 1996.

[13] Royal Decree 63/2008, The Disabled Persons Welfare and rehabilitation Law, Official Gazette (in Arabic), Muscat, 2008.

[14] Royal Decree 124/2008, The Establishment of the National Human Rights Commission, Official Gazette (in Arabic), Muscat, 2008.

[15] Royal Decree 121/2008, The Ratification of the International Convention on the Rights of Persons with Disabilities, Official Gazette (in Arabic), Muscat, 2008.

[16] Royal Decree 6/1980, The Omani national heritage protection law, Official Gazette (in Arabic), Muscat, 1980.

[17] Royal Decree 33/2002, The Law of Tourism, Official Gazette (in Arabic), Muscat, 2002.

[18] Al-Belushi, M.A.K., Archaeological legislation in the Sultanate of Oman. International Journal of Heritage Studies, 20 (1), pp. 36-53, 2014.

[19] Ministry of Tourism. Khasab Castle: Experience History. (Brochure in Arabic and English), Muscat, n.d.

[20] Museum Heritage Awards. Award Winners 2010. http://www.museumsandheritage.com/show/awards/hall-of-fame/2010award-winners. Accessed on 24.06.2014.

[21] UNESCO World Heritage Center 2014. The Forts of Rustaq and Al Hazm. http://whc.unesco.org/en/tentativelists/497/ Accessed on 17.06.204.

[22] Ministry of Tourism, Number of visitors to the forts and castles. http://www.omantourism.gov.om/wps/portal/mot/tourism/oman/home/med ia/statistics/ Accessed on 13.06.2014. 